\title{
Mobilidade do zinco e do cobre em Argissolo com aplicação de argila bentonita
}

\author{
$\overline{\text { Gilvanise A. Tito }^{1} \text {, Lucia H. G. Chaves }}{ }^{2}$ \& Hugo O. C. Guerra ${ }^{2}$
}

\begin{abstract}
RESUMO
A mobilidade dos metais pesados no solo é influenciada pelas características do solo, pela mineralogia das argilas e pelo teor do metal. Objetivando avaliar o efeito da bentonita na mobilidade do zinco e do cobre no solo, colunas de lixiviação preenchidas com um Argissolo foram submetidas a ensaios de mobilidade utilizando-se doses de bentonita $\left(0,30\right.$ e $\left.^{2} 0 \mathrm{t} \mathrm{ha}^{-1}\right)$ e concentrações de zinco e cobre, de 50, 250 e $450 \mathrm{mg} \mathrm{kg}^{-1}$. As colunas de solo foram mantidas saturadas e sob fluxo de água permanente; em seguida foram determinados densidade, velocidade do fluxo, fator de retardamento, coeficiente de dispersão-difusão e número de Peclet. Os parâmetros de transporte foram definidos através do modelo computacional DISP. A incorporação de bentonita ao solo promoveu a retenção do zinco e do cobre pelo solo, principalmente deste último, diminuindo a concentração em solução lixiviada e os riscos de contaminação do meio ambiente. A aplicação de bentonita aumentou o fator de retardamento, mas reduziu o coeficiente de dispersão-difusão do solo.
\end{abstract}

Palavras-chave: percolação, fator de retardamento, coeficiente de dispersão-difusão

\section{Zinc and copper mobility in Argisol with application of bentonite clay}

\begin{abstract}
The mobility of heavy metals in the soil is influenced by the soil, the clay mineralogy and the amount of metal. Aiming to evaluate the effect of bentonite clay on zinc and copper mobility, leaching columns of soil, filled with an Argisol, utilising increasing doses of bentonite $\left(0,30\right.$ e $\left.60 \mathrm{t} \mathrm{ha}^{-1}\right)$ and concentrations of zinc and copper (50, 250 e $450 \mathrm{mg} \mathrm{kg}^{-1}$ ) were submitted to a saturated and steady flow. The flux density, velocity, transport retardation factor, dispersion-diffusion coefficient and breakthrough curves were obtained. The transport parameters were determined using the DISP computational model. The results allow to conclude that the application of bentonite clay to the soil promoted the retention of the zinc and copper, mainly the last one, decreasing the concentration in leachate and reducing potential contamination risks. The bentonite clay application increased the soil retardation factor and decreased the dispersiondiffusion coefficients of the soil.
\end{abstract}

Key words: percolation, retardation factor, coefficient of dispersion-diffusion 


\section{INTRODUÇÃO}

O uso exagerado de fertilizantes minerais, lodo de esgoto e águas residuárias na agricultura, tem-se tornado uma atividade de risco, no que diz respeito à adição de metais pesados ao solo e na água. Esses elementos, presentes na solução do solo, podem ser lixiviados atingindo o lençol freático e, muitas vezes, os corpos de água (Paganini et al., 2004).

A maior ou menor mobilidade dos metais pesados no solo é influenciada pelas características do solo e pelo teor do metal (Oliveira \& Mattiazo, 2001). De acordo com Elbachá (1989) e Santos et al. (2010) o tipo de solo, a mineralogia das argilas, a distribuição granulométrica, a estrutura do solo, a capacidade de troca iônica, o tipo de íons adsorvidos e o teor de matéria orgânica, influenciam sensivelmente o transporte de contaminantes.

O movimento da água no solo é um dos assuntos mais estudados na física do solo devido, principalmente, à sua importância relacionada à disponibilidade de água para as plantas e ao transporte de solutos no solo. Neste contexto, diversos procedimentos têm sido propostos para reduzir a mobilidade e biodisponibilidade dos metais pesados, entre eles o processo de adsorção desses metais por superfícies adsorventes, como é o caso dos minerais de argila (Veli \& Alyuz, 2007).

As reações de adsorção-desorção podem causar uma transferência real de poluente da fase líquida para a fase sólida. A mobilidade de solutos no solo está inversamente relacionada à adsorção dos mesmos, à fração sólida ou às condições do meio que favoreçam a precipitação dos íons (Matos et al., 2001; Chaves et al., 2008). As condições que promovem a mobilidade incluem a acidificação, solos arenosos com baixa quantidade de matéria orgânica e a ausência de argila. Por outro lado, a retenção dos íons dos metais pesados usados em solução com solos minerais argilosos puros (caolinita, ilita e montmorilonita), indica alta capacidade de retenção pela argila suspensa com o aumento no $\mathrm{pH}$.

Nos últimos anos estudos vêm sendo aprofundados em relação às propriedades das argilas bentonitas, como sorventes de metais pesados, em razão do baixo custo, fácil obtenção e propriedades desses materiais (Santos et al., 2002; Rodrigues et al., 2004; Lacin et al., 2005). Por outro lado, o estado da Paraíba é, atualmente, o principal produtor dessas argilas, no Brasil (DNPM, 2011).

O fator de retardamento é definido como a capacidade de retenção ou efeito tampão do solo, para um elemento ou composto existente em um resíduo (Campos \& Elbachá, 1991). Indiretamente, sendo este fator um parâmetro que expressa a capacidade do solo em reter íons, fica clara sua dependência em relação às interações entre a fase líquida e a fase sólida, durante a percolação da solução no solo. De acordo com Matos et al. (2001) o cobre apresenta maiores valores de fator de retardamento que o zinco, encontrando também maior interação do cobre que a observada para o zinco, em diversos solos.

Segundo Genuchten \& Wierenga (1986) o coeficiente de dispersão-difusão é um parâmetro físico da equação do transporte de solutos; ele expressa dois fenômenos de transporte aditivos: a dispersão mecânica e a difusão iônica, que constituem o movimento térmico natural de constituintes dissolvidos que ocorre em razão da existência de gradientes de concentração. O número de Peclet (Pe) é usado para avaliar a importância relativa dos dois processos dispersivos. Valores pequenos de número de Peclet indicam que o transporte de difusão domina sobre o transporte de convecção. Para maiores valores do número de Peclet o transporte por convecção domina o de difusão (Gonçalves et al., 2008).

Em razão do exposto objetivou-se, com este trabalho, avaliar o efeito da argilo mineral bentonita na mobilidade do zinco e do cobre em colunas de solo, determinando os parâmetros de transporte, fator de retardamento, coeficiente de dispersão difusão, número de Peclet e as curvas de passagem para os íons zinco e cobre.

\section{Material e MÉTODOS}

A pesquisa foi conduzida utilizando-se um Argissolo Acinzentado Distrófico proveniente da Fazenda Capim II, no Município de Capim, PB. Após a coleta as amostras do solo foram secadas ao ar, destorroadas, passadas em peneira com malha de $2 \mathrm{~mm}$ de abertura e caracterizadas física e quimicamente, apresentando: areia $=868 \mathrm{~g} \mathrm{~kg}^{-1} ;$ silte $=40 \mathrm{~g} \mathrm{~kg}^{-1} ;$ argila $=$ $92 \mathrm{~g} \mathrm{~kg}^{-1}$; textura areia franca; densidade do solo $=1,56$; densidade das partículas $=2,65$; porosidade total $=39,0 \%$; $\mathrm{pH}=5,79$; condutividade elétrica: $0,37 \mathrm{dS} \mathrm{m}^{-1}$; zinco $=0,264$ $\mathrm{mg} \mathrm{kg}^{-1}$; cobre $=0,074 \mathrm{mg} \mathrm{kg}^{-1}$ e CTC $=5,00 \mathrm{cmol}_{\mathrm{c}} \mathrm{kg}^{-1}$.

$\mathrm{A}$ argila bentonita empregada neste trabalho, conhecida regionalmente por "bofe", coletada na jazida Primavera localizada no município de Boa Vista, PB, foi analisada por difração de raios-X através do equipamento XRD 6000 e a radiação utilizada foi $\mathrm{Ka}$ do $\mathrm{Cu}\left(40 \mathrm{kV}(30 \mathrm{~mA})^{-1}\right)$, com velocidade do goniômetro de $1,2^{\circ} \mathrm{min}^{-1}$ e passo de $0,02^{\circ}$. A Figura 1 representa o difratograma de raio $\mathrm{X}$ da bentonita Bofe, mostrando não apenas picos característicos do argilo mineral esmectito ou montmorilonítico, principal componente da bentonita mas também a presença, embora em menor quantidade, de picos de óxido de silício.

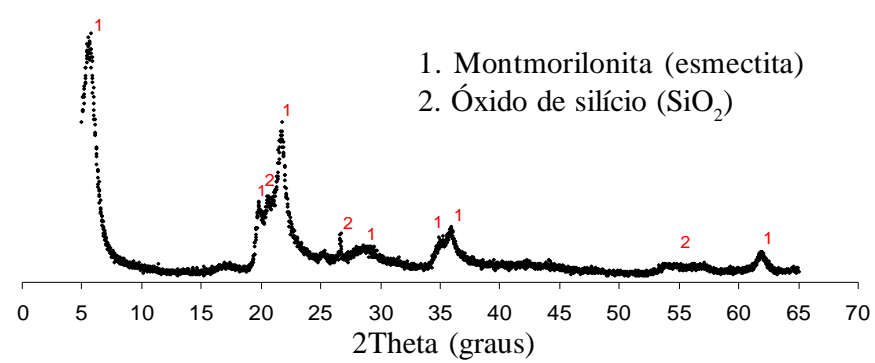

Figura 1. Difratograma da bentonita bofe obtido por difração de Raio-X

As análises químicas semiquantitativas das amostras de bentonita foram realizadas no Laboratório de Cerâmica do Departamento de Engenharia de Materiais da Universidade Federal de Campina Grande, PB, através de florescência de raio $\mathrm{X}(\mathrm{EDX})$ e do equipamento EDX 720, apresentadas: $\mathrm{SiO}_{2}=$ $76,09 \% ; \mathrm{Al}_{2} \mathrm{O}_{2}=14,51 \% ; \mathrm{Fe}_{2} \mathrm{O}_{3}=5,21 \% ; \mathrm{MgO}=2,22 \% ; \mathrm{CaO}=$ 
$0,76 \% ; \mathrm{TiO}_{2}=0,55 \% ; \mathrm{BaO}=0,19 \% ; \mathrm{K}_{2} \mathrm{O}=0,18 \% ; \mathrm{MnO}=$ $0,028 \% ; \mathrm{Cr}_{2} \mathrm{O}_{3}=0,023 \% ; \mathrm{SrO}=0,008 \% ; \mathrm{ZnO}=0,004 \%$ e Queima ao fogo $=0,23 \%$.

O solo de cada coluna de lixiviação (4 kg) foi misturado com $0 ; 0,45$ e $0,90 \mathrm{~kg}$ de bentonita, correspondentes às doses de 0 , 30 e $60 \mathrm{t} \mathrm{ha}^{-1}$. Referidas misturas foram incubadas durante 30 dias possibilitando uma provável reação entre solo e a bentonita; após este período as misturas foram novamente secadas ao ar e destorroadas.

As colunas de lixiviação utilizadas foram constituídas de tubos de PVC, de $500 \mathrm{~mm}$ de altura e $100 \mathrm{~mm}$ de diâmetro em que cada uma foi preenchida manualmente com a mistura de solo + bentonita ficando os $100 \mathrm{~mm}$ superiores disponíveis para comportar uma carga hidráulica de $80 \mathrm{~mm}$ sobre o solo; na parte inferior da coluna foi colocada uma tampa de PVC de 100 mm com um dreno adaptado no seu centro; sobre a tampa foi posta uma tela de nylon e, sobre ela, um papel de filtro de filtragem rápida para sustentação do material sólido; por fim, a coluna foi preenchida de forma a proporcionar, em toda ela, uniformidade quanto à sua densidade.

As soluções de $\mathrm{Zn}$ e $\mathrm{Cu}$ utilizadas como fontes poluentes, foram preparadas a partir de $\mathrm{ZnCl}_{2}$ e $\mathrm{CuCl}_{2} \cdot 2 \mathrm{H}_{2} \mathrm{O}$, respectivamente, nas concentrações 50, 250 e $450 \mathrm{mg} \mathrm{kg}^{-1}$, para cada elemento em estudo. Os experimentos para zinco e cobre foram conduzidos de forma individual; assim, o delineamento experimental para cada experimento foi inteiramente casualizado e os tratamentos foram distribuídos em esquema fatorial $3 \times 3$ (três doses de bentonita, três concentrações de metal), em três repetições totalizando, para cada elemento químico estudado, 27 unidades experimentais.

Inicialmente, as colunas de solo foram saturadas com água destilada, através de ascensão capilar e conectadas, em seguida, a uma garrafa de Mariotte contendo água destilada. Mantendose uma lâmina de água constante de $80 \mathrm{~mm}$ iniciou-se a percolação até se obter uma vazão constante; após a estabilização da vazão o fornecimento de água na parte superior das colunas foi interrompido, deixando drenar um volume de água igual a 1 volume de poros; em seguida foi adicionado, na sua parte superior, um volume de solução do metal correspondente a 1 volume de poros deixando-se $24 \mathrm{~h}$ em repouso; decorrido este tempo os drenos foram abertos reiniciando-se, então, o fornecimento de água e se mantendo a lâmina de $80 \mathrm{~mm}$ de altura iniciando-se, aí, a lixiviação e a coleta dos lixiviados a cada $10 \mathrm{~min}$, até completar sete coletas. Os lixiviados foram coletados em frascos de polipropileno, previamente lavados em solução de ácido clorídrico e preparados para quantificação do metal por espectrofotometria de absorção atômica. De cada unidade experimental (27 para o $\mathrm{Zn}$ e 27 para o $\mathrm{Cu}$ ) foram coletadas sete amostras do lixiviado, totalizando 378 amostras.

O volume de poros de cada coluna foi determinado pela Eq. 1:

$$
V p=\pi r^{2} h\left(1-\frac{d s}{d p}\right)
$$

\footnotetext{
em que:

$\mathrm{Vp}$ - volume de poros, $\mathrm{cm}^{3}$

$\pi$ - constante matemática $\approx 3,14$
}
$\mathrm{r} \quad$ - raio da coluna, $\mathrm{cm}$
h - comprimento da coluna, $\mathrm{cm}$
ds - densidade do solo
dp - densidade das partículas

A densidade de fluxo de cada coluna foi calculada por meio da Eq. 2:

$$
q=\frac{Q}{A}=\frac{V e}{A t}
$$

em que:

$$
\begin{array}{ll}
\mathrm{q} & \text { - fluxo, } \mathrm{cm} \mathrm{h}^{-1} \\
\mathrm{Q} & \text { - vazão, } \mathrm{cm}^{3} \mathrm{~h}^{-1} \\
\mathrm{~A} & \text { - seção transversal da coluna, } \mathrm{cm}^{2} \\
\mathrm{Ve} & \text { - volume total de efluente, } \mathrm{cm}^{3} \\
\mathrm{t} & \text { - intervalo de tempo para coletar o volume Ve }
\end{array}
$$

A velocidade de avanço da solução percolante $V$ foi definida através da Eq. 3:

$$
\mathrm{V}=\frac{\mathrm{q}}{\alpha}
$$

em que:

$$
\begin{array}{ll}
\mathrm{V} & \text { - velocidade de avanço, } \mathrm{cm} \mathrm{h}^{-1} \\
\mathrm{q} & \text { - fluxo, } \mathrm{cm} \mathrm{h}^{-1} \\
\alpha & \text { - porosidade total, } \mathrm{cm}^{3} \mathrm{~cm}^{-3}
\end{array}
$$

Os parâmetros de transporte fator de retardamento, coeficiente de difusão-dispersão e Número de Peclet, foram determinados utilizando-se o modelo computacional DISP (Programa para cálculo dos parâmetros de transporte de solutos no solo em deslocamento de fluidos miscíveis), desenvolvido no Departamento de Engenharia Agrícola da Universidade Federal de Viçosa, por Borges Júnior \& Ferreira (2006). Utilizouse deslocamento por pulso, ou seja, a solução contaminante é colocada no solo por determinado tempo fazendo-se, em seguida, a lixiviação com água destilada. Os dados de entrada que alimentaram o programa foram as concentrações do metal no lixiviado (C) para diferentes números de volume de poros adicionados (np), teor de água do solo (igual à porosidade total já que os solos foram saturados), densidade do solo, densidade de fluxo e comprimento da coluna de solo.

Com as concentrações dos íons percolados e o número de volume de poros foram traçadas as curvas de passagem para os íons zinco e cobre, de acordo com Prevedello (1996).

\section{RESULTADOS E DISCUSSÃO}

As doses crescentes de bentonita aplicadas ao solo $(0,30 \mathrm{e}$ $60 \mathrm{t} \mathrm{ha}^{-1}$ ) reduziram os valores médios do número de poros necessários para deslocar os cátions, zinco e cobre, a densidade de fluxo e a velocidade de avanço do fluxo, tanto dos solos com diferentes conteúdos de zinco como diferentes conteúdos de cobre (Tabela 1). 
Tabela 1. Valores médios do número de poros, densidade de fluxo e velocidade de avanço da solução nas colunas de solo

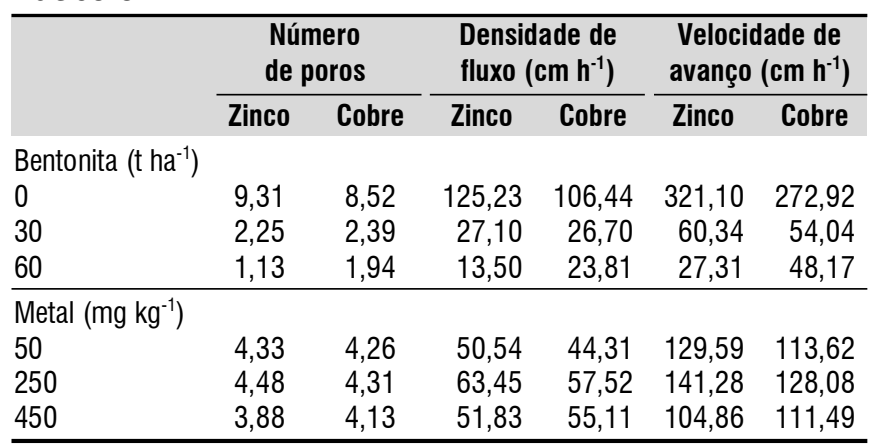

Esses resultados eram esperados uma vez que a aplicação de bentonita no Argissolo utilizado no experimento, que possui poros grandes, com elevada percolação, diminuiu a densidade do solo e, em consequência, todas as variáveis acima citadas. $\mathrm{O}$ aumento das doses de bentonita reduziu a densidade de fluxo da solução mostrando o efeito benéfico da argila ao diminuir a excessiva percolação de zinco e cobre (Tabela 1). Este efeito positivo é devido ao fato das argilas, tendo alta microporosidade, dificultarem a passagem da água e solutos no solo em virtude, também, da sua maior superfície específica, que favorece a troca catiônica reduzindo, assim, os riscos de contaminação por percolação. Segundo Jesus (2004) o processo de migração e retenção de poluentes no solo é influenciado, além de outros fatores, pela mineralogia das argilas e pela capacidade de troca de cátions do solo.

A concentração de cátions na solução do solo proporciona a competição entre eles pelos sítios de adsorção favorecendo a lixiviação daqueles que não foram retidos, fato que constitui um alerta quanto ao perigo de contaminação dos mananciais. Se a concentração de íons é maior que a capacidade de adsorção dos coloides, os íons serão lixiviados; por outro lado, quanto menor a densidade de fluxo e velocidade de avanço da solução na coluna de solo, maior é o tempo de contato entre os íons e os coloides do solo promovendo maior oportunidade de retenção dos solutos. No presente estudo o número de poros, a densidade de fluxo e a velocidade de avanço, não foram afetados, aparentemente, pela concentração dos metais, zinco e cobre (Tabela 1).

O fator retardamento expressa as interações entre as fases líquidas e sólidas que ocorrem durante a percolação da solução deslocadora no solo (Melo et al., 2006). Os valores do fator retardamento de 1,19 e 1,10 para o zinco e o cobre, respectivamente, quando não se aplicou bentonita (Tabela 2), por serem próximos da unidade, indicaram que os cátions não sofreram interações com o solo (adsorção), ou seja, que o solo foi pouco reativo. Segundo Genuchten \& Wierenga (1986), quando o solo é pouco reativo o soluto é transportado com a mesma velocidade de percolação do solvente; comportamento semelhante foi constatado por Melo et al. (2006) ao estudarem o deslocamento miscível de cátions provenientes de água residuária de mandioca em colunas de solo, com três classes texturais, areia, franco-arenosa e muito argilosa.
Tabela 2. Valores médios do fator de retardamento, coeficiente de dispersão-difusão e número de Peclet

\begin{tabular}{|c|c|c|c|c|c|c|}
\hline & \multicolumn{2}{|c|}{$\begin{array}{l}\text { Fator de } \\
\text { retardamento }\end{array}$} & \multicolumn{2}{|c|}{$\begin{array}{l}\text { Coeficiente de dispersão } \\
\text { difusão }\left(\mathrm{cm}^{2} \mathrm{~h}^{-1}\right)\end{array}$} & \multicolumn{2}{|c|}{$\begin{array}{l}\text { Número } \\
\text { de Peclet }\end{array}$} \\
\hline & Zinco & Cobre & Zinco & Cobre & Zinco & Cobre \\
\hline \multicolumn{7}{|c|}{ Bentonita $\left(\mathrm{t} \mathrm{ha}^{-1}\right)$} \\
\hline 0 & 1,19 & 1,10 & 4709,70 & 4585,93 & 170,1 & 55,06 \\
\hline 30 & 2,00 & 5,04 & 1938,00 & 3184,61 & 56,74 & 23,12 \\
\hline 60 & 4,40 & 6,13 & 141,89 & 1893,94 & 3,83 & 6,61 \\
\hline \multicolumn{7}{|c|}{ Metal $\left(\mathrm{mg} \mathrm{kg}^{-1}\right)$} \\
\hline 50 & 2,27 & 4,16 & 910,31 & 4027,37 & 77,43 & 9,98 \\
\hline 250 & 2,24 & 4,62 & 2508,70 & 2957,49 & 58,42 & 15,29 \\
\hline 450 & 3,09 & 3,50 & 3370,50 & 2679,62 & 94,80 & 59,51 \\
\hline
\end{tabular}

Em virtude da sua alta porosidade e da grande quantidade de microporos, a bentonita apresenta alta tortuosidade e alta superfície específica, características que retardam o fluxo. Desta forma se observa, na Tabela 2, que ocorreu aumento dos valores do fator de retardamento para os íons zinco e cobre, em função das doses crescentes da argila bentonita, as quais contribuem para a redução da percolação. Os valores obtidos para o fator de retardamento são semelhantes aos encontrados na literatura (Elbachá, 1989; Azevedo et al., 2003; Moreira et al., 2010), por exemplo, Elbachá (1989) e Moreira et al. (2010) constataram que os valores de fator de retardamento foram menores que 4,5 para o zinco e variaram de 2,32 a 6,40 para o cobre, respectivamente; entretanto, ao contrário do que foi comentado, Azevedo et al. (2005) constataram, para o zinco, um valor alto de fator de retardamento igual a 26,5 devido, provavelmente, à concentração da solução contaminante uma vez que, havendo sítios de cargas limitados nas colunas de lixiviação, quanto maior a quantidade de cátions presentes na solução em percolação mais rápida deverá ser sua saturação iônica (Azevedo et al., 2005).

A diminuição da densidade de fluxo da solução na coluna de solo aumentou o fator de retardamento, como constatado para o solo, em que se adicionaram $60 \mathrm{t} \mathrm{ha}^{-1}$ de bentonita; neste tratamento a densidade de fluxo para o tratamento com zinco foi 9,28 vezes menor da observada nos solos em que não se adicionou bentonita, para o caso do solo com cobre, 4,47 vezes menor. Acredita-se que as baixas densidades de fluxo da solução contaminante tenham proporcionado, aos dois cátions, maior tempo de contato com os sítios de adsorção, o que conduziu à obtenção de valores relativamente altos para o fator de retardamento.

Quando se adicionou bentonita os valores do fator de retardamento para o zinco foram, em geral, menores que os valores correspondentes ao cobre, corroborando com Martinez et al. (2001) e Matos et al. (2001) que também constataram maior interação do cobre que a observada para o zinco.

Promovendo a redução das médias dos coeficientes dispersivo-difusivo do cobre e do zinco, as dosagens crescentes de bentonita se mostraram coerentes uma vez que, de acordo com Gonçalves et al. (2008), solos mais arenosos, que apresentam velocidade de percolação elevada, promoveram maiores coeficientes de dispersão-difusão do que os solos mais argilosos. O coeficiente de dispersão-difusão pode ser 
indicativo da capacidade do solo em reter determinado soluto à medida em que a frente de umedecimento da solução aplicada avança no perfil do solo.

Os valores médios dos coeficientes de dispersão-difusão aumentaram em função dos teores de zinco, 910,31; 2508,70 e 3370,50 para as doses de 50, 250 e $450 \mathrm{mg} \mathrm{kg}^{-1}$ de zinco, respectivamente. Para Gonçalves et al. (2008) a concentração do contaminante, a densidade de fluxo e a velocidade da água influenciam na quantidade transportada, a qual é função da junção da velocidade deslocadora da solução e da existência de gradientes de concentração. No caso do cobre ocorreu o inverso, ou seja, o aumento das doses de cobre promoveu redução dos valores médios do coeficiente de dispersãodifusão de 4027,37; 2957,49 e 2679,62 para os tratamentos de 50,250 e $450 \mathrm{mg} \mathrm{kg}^{-1}$ de cobre, respectivamente.

A aplicação das doses crescentes da bentonita no solo reduziu o número de Peclet para todas as doses de zinco utilizadas. Segundo Gonçalves et al. (2008) valores pequenos de número de Peclet indicam que o transporte de difusão domina sobre o transporte de convecção; maiores valores indicam que o transporte por convecção domina o de difusão. Os maiores valores no tratamento sem bentonita (Tabela 2) sinalizaram que o deslocamento dos solutos ocorreu, sobremaneira, por convecção pois, na medida em que aumentou o conteúdo de bentonita no solo o transporte de difusão dominou sobre o de convecção cujos resultados obtidos apresentaram coerência visto que o solo sem bentonita é um solo arenoso que permite a condução de água mais facilmente e, juntamente com ela, carrega os solutos dissolvidos predominando o transporte por convecção. Quando o conteúdo de argila aumentou para 60 $\mathrm{t} \mathrm{ha}^{-1}$ de bentonita o fluxo por convecção ficou difícil passando a predominar a difusão. Segundo Quadri (1993) valores de número de Peclet superiores a 10 indicam que a convecção predomina sobre o processo de difusão.

Os resultados do estudo mostraram que, em geral, o aumento da concentração de cátions aparentemente favoreceu o transporte por convecção devido a um excesso de íons não adsorvidos pelos colóides, fato que os deixaria mais susceptíveis a este tipo de fluxo.

Quando comparados com os do cobre, os maiores números de Peclet para o zinco indicaram que este elemento é mais suscetível a ser transportado por convecção. O cobre, com menores números de Peclet, seria mais transportado por difusão, com deslocamento menor e, assim, mais retido pelo solo, corroborando com os resultados de Martinez et al. (2001).

As curvas de passagem do íon zinco e cobre para todas as concentrações e doses de bentonita testadas, foram apresentadas nas Figuras 2 e 3, respectivamente. Em todas as situações as concentrações de metais no percolado aumentaram com o tempo, até atingir uma concentração máxima para em seguida, após determinado tempo, decrescerem até se dissipar pelo efeito da diluição, concordando com Prevedello (1996).

As colunas do solo sem bentonita $\left(0 \mathrm{t} \mathrm{ha}^{-1}\right)$, que receberam teores de 50, 250 e $450 \mathrm{mg} \mathrm{kg}^{-1}$ de zinco e cobre, necessitaram de um volume de água (número de poros) superior a 8,0 para que o equilíbrio entre os íons na solução e no solo fosse atingindo (Figuras 2 e 3 ) ou seja, para que a concentração de $\mathrm{Zn}$ e $\mathrm{Cu}$ no percolado fosse reduzida ou quase zero. Tendo sido preenchidas com uma areia franca as colunas sem bentonita conferiram elevada velocidade de percolação; a presença de
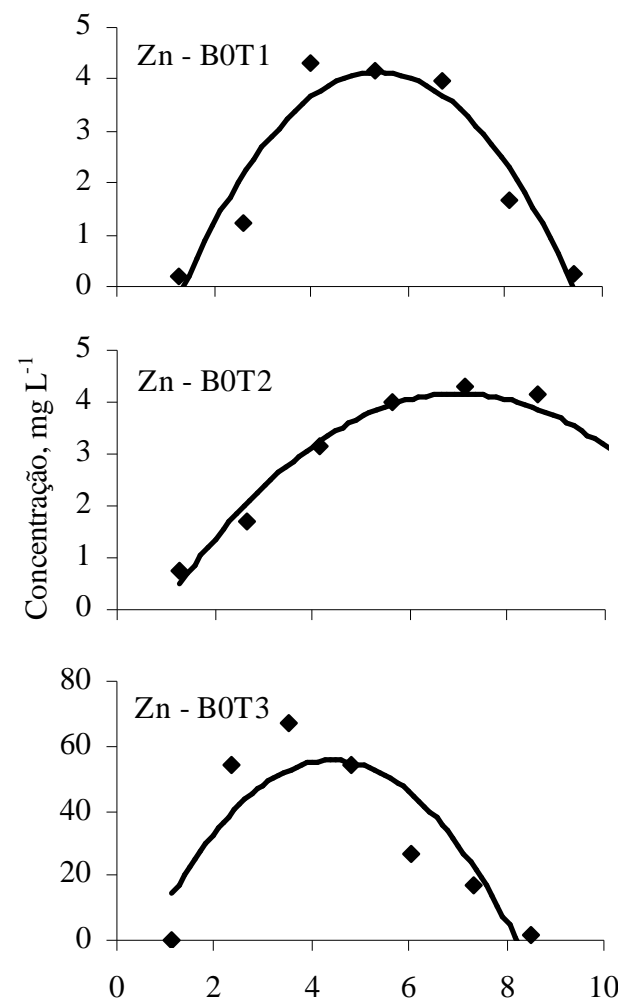
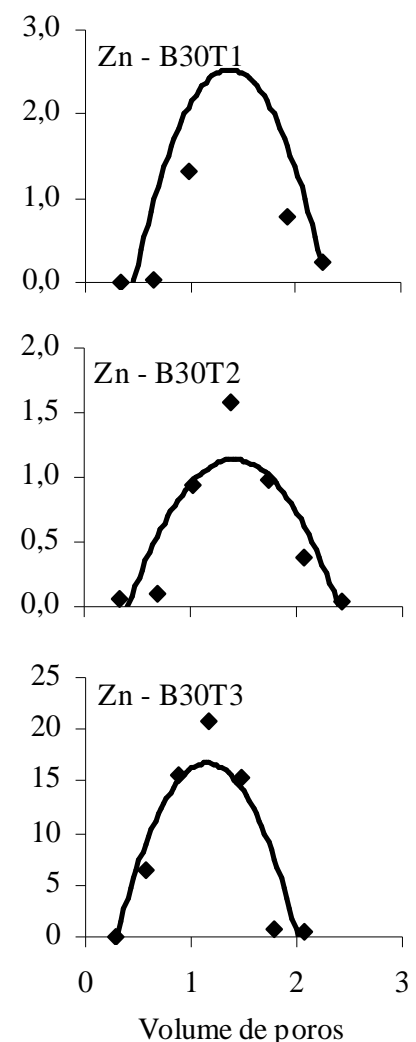
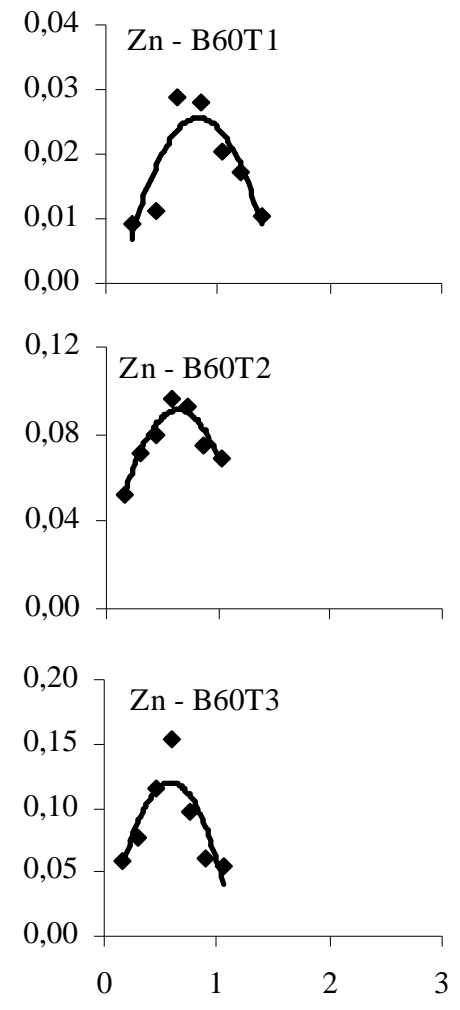

Figura 2. Curvas de passagem do zinco para os diferentes teores de zinco T1, T2 e T3 (50, 250 e $\left.450 \mathrm{mg} \mathrm{kg}^{-1}\right)$ e bentonita B0, B30 e B60 (0, 30 e $\left.60 \mathrm{t} \mathrm{ha}^{-1}\right)$ 

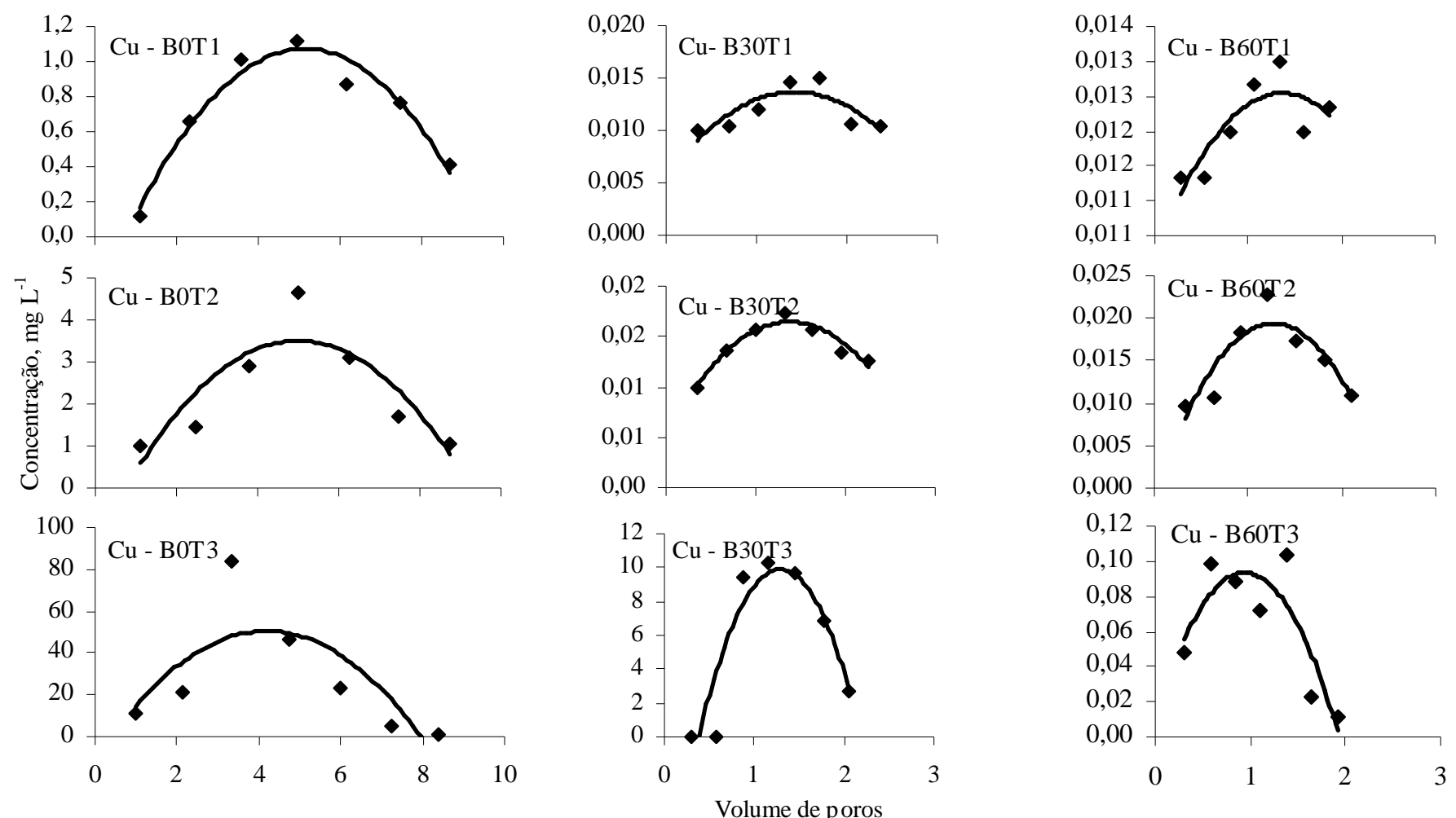

Figura 3. Curvas de passagem do cobre para os diferentes teores de cobre T1, T2 e T3 (50, 250 e $450 \mathrm{mg} \mathrm{kg}^{-1}$ ) e bentonita B0, B30 e B60 (0, 30 e $\left.60 \mathrm{t} \mathrm{ha}^{-1}\right)$

uma grande quantidade de macroporos permitiu a condução de água mais facilmente promovendo, com isto, uma adsorção menor dos referidos metais em virtude do tempo disponível ser menor para que os processos de transferência ocorram.

$\mathrm{A}$ adição de bentonita ao solo reduziu o volume de água (número de volume de poros) necessário para lixiviar o zinco do solo e reduzir a zero a concentração do metal no percolado, sugerindo que a bentonita aplicada ao solo aumentou a adsorção do zinco deixando uma concentração menor, disponível no solo para sua lixiviação. Quando se aplicaram 30 $\mathrm{t} \mathrm{ha}^{-1}$ de bentonita foram necessários, aproximadamente, 2 volumes de poros e de aproximadamente 1,5 volume de poros com a dose de $60 \mathrm{t} \mathrm{ha}^{-1}$ de bentonita (Figura 2); comportamento semelhante foi observado por Melo et al. (2006).

Para qualquer dose de bentonita aplicada as concentrações máximas de zinco obtidas nos percolados aumentaram com a concentração de zinco no solo. Para o solo sem bentonita a máxima concentração de zinco obtida no solo com $50 \mathrm{mg} \mathrm{kg}{ }^{-1}$ foi de $4 \mathrm{mg} \mathrm{L}^{-1}$; já para o solo com $450 \mathrm{mg} \mathrm{kg}^{-1}$ esta foi de aproximadamente $60 \mathrm{mg} \mathrm{L}^{-1}, 15$ vezes maior e no solo com 60 t ha ${ }^{-1}$ de bentonita e $50 \mathrm{mg} \mathrm{kg}^{-1}$ de zinco a máxima concentração de zinco obtida no percolado foi de $0,025 \mathrm{mg} \mathrm{L}^{-1}$; no solo com $450 \mathrm{mg} \mathrm{kg}^{-1}$ de zinco esta foi de aproximadamente $0,125 \mathrm{mg} \mathrm{L}^{-1}$, 5 vezes maior.

As equações das curvas de passagem do zinco submetidas aos tratamentos são apresentadas na Tabela 3 .

Tal comportamento pode ser observado nas curvas de passagem para o cobre, apresentadas na Figura 3. A aplicação de bentonita ao solo reduziu o volume de água (número de volume de poros) necessário para lixiviar o cobre do solo e reduzir, quase a zero, a concentração do metal no percolado o que sugere que
Tabela 3. Equações das curvas de passagem do zinco submetidas aos tratamentos doses de bentonita (B0, B30 e B60 t ha-1) e doses de zinco (T1-50, T2-250 e T3-450 $\mathrm{mg} \mathrm{kg}^{-1}$ )

\begin{tabular}{llc}
\hline Tratamentos & \multicolumn{1}{c}{$\begin{array}{c}\text { Equaçóes das curvas } \\
\text { de passagem do zinco }\end{array}$} & $\mathbf{R}^{2}$ \\
B0 T1 & $y=-0,256 x^{2}+2,759 x-3,2912$ & 0,90 \\
B30 T1 & $y=-3,0038 x^{2}+8,2292 x-3,1043$ & 0,66 \\
B60 T1 & $y=-0,0518 x^{2}+0,0856 x-0,0098$ & 0,79 \\
B0 T2 & $y=-0,1124 x^{2}+1,5736 x-1,3424$ & 0,97 \\
B30 T2 & $y=-1,1483 x^{2}+3,2318 x-1,1359$ & 0,76 \\
B60 T2 & $y=-0,1673 x^{2}+0,2145 x+0,0224$ & 0,92 \\
B0 T3 & $y=-3,8531 x^{2}+33,995 x-19,38$ & 0,75 \\
B30 T3 & $y=-22,799 x^{2}+52,488 x-13,456$ & 0,80 \\
B60T3 & $y=-0,3612 x^{2}+0,4263 x-0,0057$ & 0,71 \\
\hline
\end{tabular}

a bentonita aplicada ao solo aumentou a adsorção do cobre deixando uma concentração menor no solo, disponível para sua lixiviação. Referidos resultados estão de acordo com Sanchez et al. (1999) que verificaram, estudando a capacidade de alguns minerais silicatados em adsorver metais pesados, que a bentonita, dentre outros minerais de argila, foi a que apresentou maior capacidade de adsorção de zinco. Por sua vez, Araújo et al. (2009) constataram, estudando a adsorção de Zn pela bentonita (bofe calcinada) que o processo de adsorção é exotérmico e que as interações argila-Zn ocorreram de forma espontânea; esses autores mostraram que a argila bentonita pode ser usada para remoção de íons Zn e que apresenta potencial para substituir outros adsorventes mais caros, em razão da sua alta disponibilidade, baixo custo e boas propriedades de adsorção.

As argilas bentonitas e vermiculitas promovem um importante processo de adsorção do cobre enquanto a área 
superficial, o tamanho da partícula e a capacidade de troca de cátions influenciam sua remoção pelas argilas (Santos et al., 2002). Segundo eles, a remoção do cobre pela bentonita pode ser considerada um processo de troca iônica dependente da faixa de $\mathrm{pH}$ do meio.

Para qualquer dose de bentonita aplicada as concentrações máximas de cobre obtidas nos percolados aumentaram com a concentração de cobre no solo. Para o solo sem aplicação de bentonita a máxima concentração de cobre constatada no solo com $50 \mathrm{mg} \mathrm{kg}^{-1}$ foi de $1,2 \mathrm{mg} \mathrm{L}^{-1}$; já para o solo tratado com 450 $\mathrm{mg} \mathrm{kg}^{-1}$ a máxima concentração de cobre foi de aproximadamente $50 \mathrm{mg} \mathrm{L}^{-1}, 42$ vezes maior; no solo tratado com $60 \mathrm{t} \mathrm{ha}^{-1} \mathrm{de}$ bentonita e $50 \mathrm{mg} \mathrm{kg}^{-1}$ de cobre a máxima concentração de cobre constatada no percolado foi de $0,013 \mathrm{mg} \mathrm{L}^{-1}$; já no solo tratado com $450 \mathrm{mg} \mathrm{kg}^{-1}$ de cobre a máxima concentração no percolado foi de aproximadamente $0,09 \mathrm{mg} \mathrm{L}^{-1}, 7$ vezes maior.

As equações das curvas de passagem do cobre submetidas aos tratamentos estudados são apresentadas na Tabela 4.

Tabela 4. Equações das curvas de passagem do cobre submetidas aos tratamentos doses de bentonita (B0, B30 e B60 t ha-1) e doses de cobre (T1-50, T2-250 e T3-450 $\mathrm{mg} \mathrm{kg}^{-1}$ )

\begin{tabular}{clc}
\hline Tratamentos & \multicolumn{1}{c}{$\begin{array}{c}\text { Equaçóes das curvas } \\
\text { de passagem do cobre }\end{array}$} & $\mathbf{R}^{2}$ \\
B0 T1 & $y=-0,0556 x^{2}+0,5707 x-0,3919$ & 0,95 \\
B30 T1 & $y=-0,0040 x^{2}+0,0114 x-0,0056$ & 0,66 \\
B60 T1 & $y=-0,0012 x^{2}+0,0033 x-0,0103$ & 0,69 \\
B0 T2 & $y=-0,1930 x^{2}+1,9325 x-1,3318$ & 0,76 \\
B30 T2 & $y=-0,0059 x^{2}+0,0162 x+0,0053$ & 0,91 \\
B60 T2 & $y=-0,0126 x^{2}+0,032 x-0,0009$ & 0,79 \\
B0 T3 & $y=-3,5242 x^{2}+29,472 x-11,12$ & 0,59 \\
B30 T3 & $y=-11,942 x^{2}+30,775 x-9,9349$ & 0,83 \\
B60 T3 & $y=-0,0939 x^{2}+0,1764 x+0,0107$ & 0,73 \\
\hline
\end{tabular}

\section{ConclusõEs}

1. A incorporação de bentonita ao solo reduziu a densidade, a velocidade de fluxo e o fator de retardamento do fluxo aumentando, desta forma, a adsorção do zinco e do cobre.

2. O transporte dos cátions zinco e cobre no solo com bentonita foi maior por difusão que por convecção.

3. O cobre é mais fortemente adsorvido pelo complexo solobetonita do que o zinco.

\section{AgRadeCIMENTOS}

Ao Conselho Nacional de Desenvolvimento Científico e Tecnológico (CNPq) pela concessão de bolsa de Doutorado.

À Bentonit União Indústria e Comércio Ltda., pela doação da bentonita.

\section{LITERATURA CITADA}

Araújo, A. L. P.; Silva, M. C. C.; Gimenes, M. L.; Barros, M. A. S. Estudo termodinâmico da adsorção de zinco em argila bentonita bofe calcinada. Scientia Plena, v.5, p.1-6, 2009.
Azevedo, I. C. D.; Azevedo, R. F.; Carvalho, A. L.; Matos, A. T.; Nascentes, C. R. Contaminação do solo e de águas subsuperficiais por metais pesados no antigo lixão de Viçosa, MG, Brasil. Geotecnia, v.98, p.23-55, 2003.

Azevedo, I. C. D.; Nascentes, C. R.; Matos, A. T.; Azevedo, R. F. Determinação de parâmetros de transporte de metais pesados em Latossolo compactado. Revista Brasileira de Engenharia Agrícola e Ambiental, v.9, p.623-630, 2005.

Borges Júnior, J. F.; Ferreira, P. A. Equações e programa computacional para cálculo do transporte de solutos do solo. Revista Brasileira de Engenharia Agrícola e Ambiental, v.10, p.604-611, 2006.

Campos, T. M.; Elbachá, A. T. Avaliação do fator de retardamento por adsorção no transporte de zinco em solos argilosos. In: Simpósio Sobre Barragens de Rejeitos E Disposição de Resíduos - REGEO’91, Rio de Janeiro. Anais... Rio de Janeiro: Associação Brasileira de Mecânica dos Solos, 1991. p.271-282.

Chaves, L. H. G.; Souza, R. S.; Tito, G. A. Adsorção de zinco em Argissolos do Estado da Paraíba: efeito do pH. Revista Ciência Agronômica, v.39, p.511-516, 2008.

DNPM - Departamento Nacional de Produção Mineral. Sumário Mineral 2011. Bentonita. <https://sistemas.dnpm.gov.br/ publicacao/mostra_imagem.asp?IDBancoArquivoArquivo= 6358> 3 Maio 2012.

Elbachá, A. T. Estudo da influência de alguns parâmetros no transporte de massa em solos argilosos. Rio de Janeiro: PUC, 1989. 178p. Dissertação Mestrado

Genuchten, M. T. van; Wierenga, P. J. Solute dispersion coefficients and retardation factors. In: Klute, A. (ed.) Methods of soil analysis, Part 1. Physical and mineralogical methods. v.44, Madison: ASA, 1986. p.1025-1054.

Gonçalves, A. D. M. A.; Miranda, P. R.; Sabadin, J. F. G.; Kamogawa, M. Y. Temperature effect in potassium and nitrate íons in soil transport. Engenharia Agrícola, v.28, p.438-447, 2008.

Jesus, S. C. Difusão de zinco em camada compactada de solo residual de gnaisse. Viçosa: UFV, 2004. 90p. Tese Doutorado

Lacin, O.; Bayrak, B.; Korkut, O.; Sayan, E. Modeling of adsorption and ultrasonic desorption of cadmium (II) and zinc (II) on local bentonite. Journal of Colloid and Interface Science, v.292, p.330-335, 2005.

Matos, A. T.; Fontes, M. P. F.; Costa, L. M.; Martinez, M. A. Retardation factors and the dispersion-diffusion coefficients of $\mathrm{Zn}, \mathrm{Cd}, \mathrm{Cu}$ and $\mathrm{Pb}$ in soils from Viçosa-MG, Brazil. Transaction of the American Society of Agricultural Engineers, v.42, p.903-910, 2001.

Martinez, M. A.; Ramos, V. B. N,; Matos, A. T.; Oliveira, R. A. Influência da competição catiônica nos valores de fator de retardamento e coeficiente de dispersão-difusão de zinco e cobre no solo. Revista Brasileira de Engenharia Agrícola e Ambiental, v.5, p.211-215, 2001.

Melo, R. F. de; Ferreira, P. A.; Matos, A. T. ; Ruiz, H. A.; Oliveira, L. B de. Deslocamento miscível de cátions básicos provenientes da água residuária de mandioca em colunas de solo. Revista Brasileira de Engenharia Agrícola e Ambiental, v.10, p.456-465, 2006. 
Moreira, D. A.; Martinez, M. A.; Souza, J. A. R.; Matos, A. T.; Reis, C.; Barros, F. M. Fatores de retardamento e coeficientes de dispersão-difusão de metais pesados em resíduos da construção civil e demolição. Revista Ambiente \& Água, v.5, p.77-86, 2010.

Oliveira, F. C.; Mattiazzo, M. E. Mobilidade de metais pesados em um Latossolo Amarelo distrófico tratado com lodo de esgoto e cultivado com cana-de-açúcar. Scientia Agricola, v.58, p.807-812, 2001.

Paganini, W. S.; Souza, A.; Bocchiglieri, M. M. Avaliação do comportamento de metais pesados no tratamento de esgotos por disposição no solo. Engenharia Sanitária e Ambiental, v.9, p.225-239, 2004.

Prevedello, C. L. Física de solos com problemas resolvidos. Curitiba: SAEFAS. 1996. 446p.

Quadri, M. G. N. Transferts de solutes dans les sols saturés et non saturés application au pentachlorophenol. France: Universite of Grenoble, 1993. 204p. Tese Doutorado
Rodrigues, M. G F.; Silva, M. L. P.; Silva, M. G. C. Caracterização da argila bentonítica para utilização na remoção de chumbo de efluentes sintéticos. Cerâmica, v.50, p.190-196, 2004.

Sanchez, A. G.; Ayuso, E. A.; Blas, O. J. Sorption of heavy metal from industrial waste by low-cost mineral silicates. Clay Minerals, v.34, p.469-477, 1999.

Santos, C. P. F.; Melo, D. M. A.; Melo, M. A. F.; Sobrinho, E. V. Caracterização e usos de argilas bentonitas e vermiculitas para adsorção de cobre (II) em solução. Cerâmica, v.48, p.178$182,2002$.

Santos, J. S. dos; Lima, V. L. A. de; Borges Júnior, J. C. F.; Silva, L. V. B. D.; Azevedo, C. A. V.de. Mobilidade de solutos em colunas de solo com água residuária doméstica e de suinocultura. Revista Brasileira de Engenharia Agrícola e Ambiental, v.14, p.1226-1233, 2010.

Veli, S.; Alyuz, B. Adsorption of copper and zinc from aqueous solutions by using natural clay. Journal of Hazardous Materials, v.149, p.226-233, 2007. 